\title{
Método para Inoculação de Ferrugem da Cana-de-açúcar em Segmentos de Folhas
}

\author{
Ely O. Garcia ${ }^{1}$, Marcos V. Casagrande ${ }^{2}$, Alejandro M. Rago ${ }^{3}$ \& Nelson S. Massola Jr. ${ }^{1}$ \\ ${ }^{1}$ Departamento de Entomologia, Fitopatologia e Zoologia Agrícola, ESALQ, Universidade de São Paulo, Cx. Postal 09, \\ CEP 13418-900, Piracicaba, SP, Brasil, e-mail: nmassola@esalq.usp.br; ${ }^{2}$ Centro de Tecnologia Canavieira, Cx. Postal 162, \\ CEP 13400-970, Piracicaba, SP, Brasil; ${ }^{3}$ INTA EEA Famaillá \\ Ruta provincial 301 Km 32, CC 11(4132) Famaillá, Tucumán, Argentina
}

Autor para correspondência: Nelson S. Massola Jr.

GARCIA, E.O., CASAGRANDE, M.V., RAGO, A.M. \& MASSOLA Jr., N.S. Método para inoculação de ferrugem da cana-de-açúcar em segmentos de folhas. Fitopatologia Brasileira 32:253-256. 2007.

\begin{abstract}
RESUMO
A reação de genótipos de cana-de-açúcar às populações de Puccinia melanocephala é intensamente influenciada por condições ambientais, dificultando as avaliações de genótipos em condições de campo. O trabalho visou desenvolver um método de inoculação de ferrugem em segmentos de folhas, sob condições ambientais controladas. Os segmentos foram obtidos de plantas com 30 dias de idade da variedade suscetível SP70-1143. Estes foram inoculados ( 2 x $10^{4}$ esporos viáveis/ $\mathrm{mL}$ ) e acondicionados em tubos de ensaio. Os tratamentos consistiram em diferentes condições de incubação, considerando as variáveis (i) uso ou não de câmara úmida após a inoculação; (ii) imersão de $1 / 4 \mathrm{ou} 3 / 4$ do segmento no líquido do tubo e (iii) adição ou não de benzimidazol na água do tubo. O melhor tratamento consistiu na imersão de 3/4 dos segmentos em tubos com água, sem câmara úmida aplicada após a inoculação. Após incubação $\left(21^{\circ} \mathrm{C} \pm 1{ }^{\circ} \mathrm{C}, 12 \mathrm{~h}\right.$ de fotoperíodo), os segmentos mantiveram-se viáveis por até 20 dias e apresentaram bom desenvolvimento de ferrugem. O método mostrou resultados equivalentes quando comparado à inoculação de plantas inteiras de três variedades, permitindo discriminar eficientemente suas reações à ferrugem.
\end{abstract}

Palavras-chave adicionais: Saccharum sp., seleção de genótipos.

\begin{abstract}
An inoculation method for sugarcane rust in leave segments

The reaction of sugarcane to Puccinia melanocephala Syd. \& P. Syd. populations is intensely influenced by environmental conditions, make it difficult to conduct field evaluations of genotypes. This work aimed to develop a method for rust inoculation in leaf segments. The segments were obtained from 30 -day-old plants of the susceptible variety SP70-1143. These were inoculated $\left(2 \times 10^{4}\right.$ viable spores $\left./ \mathrm{mL}\right)$ and kept in test tubes. The treatments consisted of different incubation conditions, considering the variables (i) use or not of wet chamber after the inoculation; (ii) immersion of $1 / 4$ or $3 / 4$ of the section in the liquid contained in the test tube and; (iii) addition or not of benzimidazole in the water of the tube. The best treatment consisted of immersion of $3 / 4$ of the section in test tubes containing water, with no moist chamber after the inoculation. After incubation $\left(21^{\circ} \mathrm{C} \pm 1{ }^{\circ} \mathrm{C}, 12 \mathrm{~h}\right.$ of photoperiod) the sections remained viable for 20 days and showed good rust development. The method showed similar results when compared to the inoculation of whole plants of 3 varieties, making it possible to discriminate efficiently their reactions to rust.
\end{abstract}

Additional keywords: Saccharum sp., screening tests.

$\mathrm{O}$ conhecimento da reação das variedades às principais doenças de cana-de-açúcar é essencial para os programas de melhoramento, permitindo o correto direcionamento dos cruzamentos para obtenção de variedades resistentes (Coelho et al., 1990). Nos países onde a ferrugem da cana-de-açúcar (Puccinia melanocephala Syd. \& P. Syd.) ocorre, a obtenção de variedades resistentes está entre os principais objetivos destes programas (Copersucar, 1986).

Além da dificuldade na identificação de níveis de resistência desejáveis (Cardoso et al., 1988), muitas vezes variantes ambientais podem interferir na segurança dos testes. Isto se deve ao fato desta doença ser significativamente influenciada por fatores ambientais
(Purdy et al., 1983; Stomayor et al., 1983; Taylor, 1992). Browder (1964) descreveu um método de inoculação de ferrugem do trigo (Puccinia graminis Pers.) em segmentos de folhas, sob condições ambientais controladas. Este método consistiu em inocular os segmentos e incubá-los em tubos de ensaio contendo solução de benzimidazol para preservação da clorofila (Person et al., 1957; Samborski et al., 1958).

Este trabalho visou adaptar o método do patossistema ferrugem $\mathrm{x}$ trigo, descrito por Browder (1964), para o patossistema cana-de-açúcar x ferrugem, de forma a permitir grande número de inoculações em condições ambientais controladas, auxiliando os programas de melhoramento. 
Segmentos de folhas com aproximadamente 10 $\mathrm{cm}$ foram obtidos a partir de plantas sadias de cana-deaçúcar com 30 dias de idade da variedade SP70-1143 (suscetível), cultivadas em casa-de-vegetação. Utilizouse somente o terço médio de cada folha +1 (primeira folha que apresenta lígula visível). Para cada tratamento, 20 segmentos foram inoculados com suspensão de esporos e outros 20 receberam água, para fins de controle. A inoculação consistiu na aplicação, por pincelamento, de uma suspensão de esporos $\left(2 \times 10^{4}\right.$ esporos viáveis/ $\mathrm{mL}$ ), sobre a parte abaxial dos segmentos de folhas. Previamente testou-se a viabilidade dos esporos, por meio da germinação em ágar. Os segmentos não foram lavados ou desinfestados antes das inoculações.

Os segmentos foram, então, acondicionados em tubos de ensaio. Os tratamentos consistiram na combinação das seguintes condições de incubação dos segmentos: (i) uso ou não de câmara úmida ( $24 \mathrm{~h}$ ) posterior à inoculação; (ii) presença de água ou solução de benzimidazol $(60 \mathrm{mg} / \mathrm{L})$ no interior do tubo; (iii) imersão de $1 / 4$ ou $3 / 4$ do segmento no líquido do tubo. A câmara úmida consistiu em incubar por $24 \mathrm{~h}$, a 21 ${ }^{\circ} \mathrm{C} \pm 1{ }^{\circ} \mathrm{C}$, sob $12 \mathrm{~h}$ de fotoperíodo os segmentos no interior de caixas de plástico $(11 \times 11 \mathrm{~cm})$ fechadas, contendo papel de filtro umedecido no fundo. Nestas caixas, os segmentos foram apoiados sobre lâminas de microscopia. Para os tratamentos sem câmara úmida, nos quais os segmentos foram inoculados e imediatamente inseridos nos tubos, estes permaneceram, durante as primeiras 24 horas, inclinados $\left(45^{\circ}\right)$ visando reduzir o escorrimento do inóculo para o fundo do tubo.

Os tubos de cada tratamento permaneceram em incubadora B.O.D. a $21{ }^{\circ} \mathrm{C} \pm 1{ }^{\circ} \mathrm{C}, 12 \mathrm{~h}$ de fotoperíodo por 20 dias. A avaliação da ferrugem foi realizada no $14^{\circ}$ dia após a inoculação, por meio da escala diagramática proposta por Amorim et al. (1987). O delineamento estatístico utilizado foi inteiramente casualizado, com 20 repetições para cada tratamento. Cada tubo contendo um segmento de folha inoculado foi considerado como uma parcela experimental.
O método selecionado na etapa anterior foi testado para três genótipos de cana-de-açúcar: SP70-1143, SP911397 e R570, respectivamente caracterizadas como suscetível, intermediária e resistente à ferrugem, pelas diferenças na severidade observadas em campo (R.A. Sordi, Centro de Tecnologia Canavieira, informação pessoal). Para isto, segmentos de folhas destas variedades foram inoculados $\left(2 \times 10^{4}\right.$ esporos viáveis $\left./ \mathrm{mL}\right)$ e submetidos à incubação segundo o método citado acima. Inocularam-se também folhas +1 de plantas inteiras, com 30 dias de idade, das mesmas variedades, mantidas em vasos de plástico de $0,3 \mathrm{~L}$ contendo substrato Plantimax para fins de comparação das reações. A câmara úmida aplicada às plantas inteiras foi realizada colocando-as no interior de sacos de plástico umedecidos, por $24 \mathrm{~h}$, a $21^{\circ} \mathrm{C}$ $\pm 1^{\circ} \mathrm{C}$, sob fotoperíodo de $12 \mathrm{~h}$, no interior de incubadora tipo B.O.D. Após a retirada da câmara úmida, plantas inteiras e tubos contendo segmentos de folhas inoculados permaneceram nestas mesmas condições por 20 dias. A avaliação da ferrugem, tanto nos segmentos de folhas quanto nas plantas inteiras, foi realizada no $14^{\circ}$ dia após a inoculação, por meio da escala diagramática proposta por Amorim et al. (1987). Para confirmação da eficiência do método, o experimento foi realizado três vezes, em delineamento estatístico inteiramente casualizado, com 20 repetições.

Para a análise estatística de ambas as etapas do trabalho, os dados originais foram transformados em $\sqrt{ }(x+0,5)$, onde $x=\%$ de área foliar doente e, em seguida, foram submetidos à análise de variância e teste de Tukey para comparação de médias.

$\mathrm{O}$ uso de câmara úmida posterior à inoculação não apresentou efeitos evidentes sobre a doença. Porém, severidade significativamente maior da ferrugem foi observada naqueles segmentos com $3 / 4$ de seu comprimento submerso (Tabela 1). Os segmentos mantidos nos tratamentos que utilizaram a imersão apenas da extremidade da folha ( $1 / 4$ do segmento) em água ou solução de benzimidazol apresentaram maior amarelecimento (dados não apresentados). A solução de benzimidazol não

TABELA 1 - Efeito do método de incubação de segmentos de folhas de cana-de-açúcar (SP70-1143) inoculados com Puccinia melanocephala. Os resultados estão expressos em porcentagem de área foliar média atacada pelo patógeno

\begin{tabular}{|c|c|c|c|c|c|c|c|}
\hline \multicolumn{3}{|c|}{ Sol. b enzimidazol ${ }^{1}$} & \multicolumn{4}{|c|}{ Água desti lada ${ }^{2}$} & \multirow{3}{*}{ C.V. $(\%)$} \\
\hline \multirow{2}{*}{$\frac{\text { Câmara úmida }}{\text { 1/4_Sub. }{ }^{1} \text { 3/4_Sub. }{ }^{2}}$} & \multicolumn{2}{|c|}{$s / c$. úmida } & \multicolumn{2}{|c|}{ Câmara úmida } & \multicolumn{2}{|c|}{ s/c. úmida } & \\
\hline & 1/4_Sub. & 3/4_Sub. & 1/4_Sub. & 3/4_Sub. & 1/4_Sub. & 3/4_Sub. & \\
\hline $3,25 \mathrm{c}^{*}$ & $4,30 \mathbf{c}$ & $6,28 \mathbf{b}$ & $2,62 \mathbf{c}$ & $8,32 \mathbf{a}$ & $3,22 \mathbf{c}$ & $8,70 \mathbf{a}$ & 10,67 \\
\hline
\end{tabular}


mostrou vantagens em relação à água no que se refere à manifestação da ferrugem e à preservação da clorofila. Com base nestes resultados, o método selecionado consistiu na imersão de $3 / 4$ dos segmentos em tubos com água, sem realização de câmara úmida após a inoculação. Nestas condições, os segmentos mantiveram-se verdes por até 20 dias e apresentaram bom desenvolvimento de ferrugem. Desta forma, pode-se eliminar a utilização de solução preservante de benzimidazol, tornando o método mais prático e barato.

No segundo ensaio, ambos os métodos de inoculação permitiram discriminar eficientemente a reação à ferrugem das três variedades inoculadas (Figura 1; Tabela 2), e mostraram-se equivalentes. Portanto, ambos os métodos podem ser aplicados para inoculações de folhas de cana-de-açúcar. Entretanto, o método de inoculação em segmentos revelou-se mais prático devido à facilidade da realização de maior número

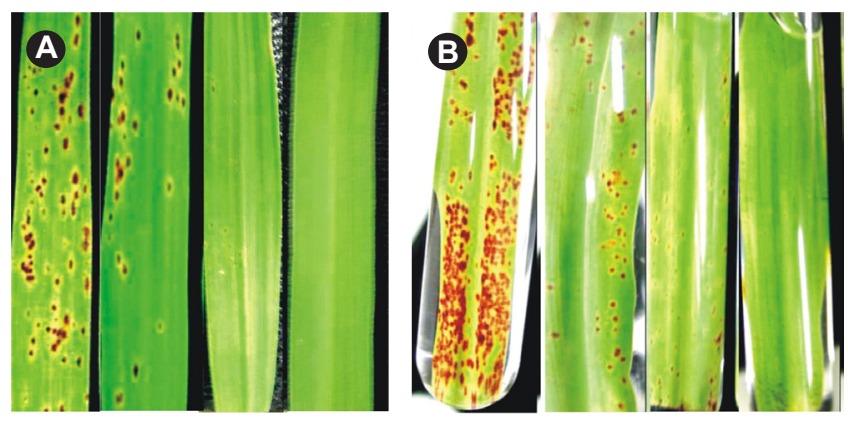

FIG. 1 - Sintomas de ferrugem em folhas de cana-de-açúcar provenientes de plantas inteiras (A) e em segmentos de folhas (B) com 30 dias inoculadas com urediniósporos de Puccinia melanocephala. Da esquerda para direita: variedades SP70-1143 (suscetível), SP911397 (intermediária), R570 (resistente) e o controle. de inoculações, além de permitir melhor controle das condições ambientais.

Os programas de melhoramento genético da cana-de-açúcar, no Brasil e no mundo, de modo geral, avaliam a reação dos genótipos à ferrugem baseando-se em ensaios de campo. No entanto, este tipo de avaliação depende da ocorrência de condições ambientais favoráveis à doença e, dessa forma, está sujeita a falhas. Sendo assim, o método de inoculação descrito poderia ser empregado paralelamente aos ensaios de campo, revelando-se útil naqueles anos onde as condições não fossem favoráveis às epidemias de ferrugem. Por outro lado, poderia ser empregado em seleções preliminares de genótipos, permitindo que fossem levados aos ensaios de campo somente os mais promissores. Isto poderia ser realizado mesmo em épocas do ano nas quais a ferrugem não ocorre epidemicamente, por meio de inoculação de urediniósporos preservados. Um eficiente método de preservação de urediniósporos de P. melanocephala foi descrito por Garcia et al. (2007).

O método mostrou ser simples, de baixo custo e válido para as condições aqui descritas. No entanto, antes de ser utilizado pelos programas de melhoramento, necessita ser testado em outras condições e, principalmente, com um número maior de genótipos para comprovar sua correlação com respostas de campo.

Outras vantagens e aplicações deste método podem ser enumeradas, como: avaliar diferentes populações do patógeno (inclusive de outros países) sem expô-los ao ambiente, evitando risco de disseminação; diminuir o espaço físico necessário para as avaliações; controlar mais efetivamente as condições experimentais, possibilitando a reprodução fiel do método; impedir contaminações indesejadas entre plantas, por ocasião da realização de testes com diferentes isolados.

TABELA 2 - Avaliação da resistência de variedades de cana-de-açúcar à ferrugem utilizando o método de inoculação em segmentos de folhas $(\mathbf{S})$ e em plantas inteiras $(\mathbf{P})$. Os resultados estão expressos em porcentagem de área foliar média com sintomas

\begin{tabular}{|c|c|c|c|c|c|c|}
\hline \multirow[t]{2}{*}{ Varied ade } & \multicolumn{2}{|c|}{$1^{\circ}$ ensaio } & \multicolumn{2}{|c|}{$2^{\circ}$ ensaio } & \multicolumn{2}{|c|}{$3^{\circ}$ ensaio } \\
\hline & $\mathbf{S}$ & $\mathbf{P}$ & $\mathbf{S}$ & $\mathbf{P}$ & $\mathbf{S}$ & $\mathbf{P}$ \\
\hline SP70-1143 (suscetível) & $3,10 \mathbf{a}$ * & $7,13 \mathbf{a}$ & $2,20 \mathbf{a}$ & $4,70 \mathbf{a}$ & $16,60 \mathbf{a}$ & $6,20 \mathbf{a}$ \\
\hline $\begin{array}{l}\text { SP91-1397 } \\
\text { (intermediária) }\end{array}$ & $0,80 \mathbf{b}$ & $1,10 \mathbf{b}$ & $0,90 \mathbf{b}$ & $1,00 \mathbf{b}$ & $2,60 \mathbf{b}$ & $2,00 \mathbf{b}$ \\
\hline $\begin{array}{l}\text { R570 } \\
\text { (resistente) }\end{array}$ & $0,00 \mathbf{c}$ & $0,30 \mathbf{c}$ & $0,00 \mathbf{c}$ & $0,20 \mathbf{c}$ & $0,50 \mathbf{b}$ & $0,10 \mathbf{b}$ \\
\hline C.V. (\%) & 6,53 & 7,99 & 10,64 & 2,11 & 16,65 & 17,29 \\
\hline
\end{tabular}




\section{AGRADECIMENTOS}

Os autores agradecem à FAPESP pela concessão de bolsa de Iniciação Científica ao primeiro autor (Proc. $\mathrm{n}^{\circ}$ 04/07990-7).

\section{REFERÊNCIAS BIBLIOGRÁFICAS}

AMORIM, L., BERGAMIN FILHO, A., SANGUINO, A., CARDOSO, C.O.N., MORAES, V.A. \& FERNANDES, C.R. Metodologia de avaliação de ferrugem da cana-de-açúcar (Puccinia melanocephala). Boletim Técnico Copersucar 39:13-16. 1987.

BROWDER, L.E. A modified detached-leaf culture technique for study of cereal rust. Plant Disease Reporter 48:906-908. 1964.

CARDOSO, C.O.N., FERNANDES, R.G., AMORIM, L., CASAGRANDE, M.V. \& MORAES, V.A. Etiologia do carvão e da ferrugem da cana-de-açúcar - Efeito da temperatura na germinação dos esporos. Boletim Técnico Copersucar 43:13-18. 1988.

COELHO, J.A, SORDI, R.A, CASAGRANDE, M.V. \& BRAGA Jr., R.L.C. Reação ao carvão e a ferrugem da coleção de variedades da Copersucar I - Variedades estrangeiras. Boletim Técnico
Copersucar 49:21-25. 1990.

COPERSUCAR. Ferrugem da cana-de-açúcar e sua constatação no município de Capivari. Boletim Técnico Copersucar Ed. Esp. 1986.

GARCIA, E.O., CASAGRANDE, M.V., RAGO, A. \& MASSOLA Jr., N.S. Preservação de urediniósporos de Puccinia melanocephala, agente causal de ferrugem em cana-de-açúcar. Summa Phytopathologica 33:49-53. 2007.

PERSON, C., SABORSKI, D.J. \& FORESYTH, F.R. Effect of benzimidazole on wheat leaves. Nature 180:1294-1295. 1957.

PURDY, L.H., LIU, L.J. \& DEAN, J.L. Sugarcane rust, a newly important disease. Plant Disease 67:1292-1296. 1983.

SAMBORSKI, D.J., FORSYTH, R.F. \& PERSON, C. Metabolic changes in detached wheat leaves floated on benzimidazole and effect of theses changes on rust reaction. Canadian Journal of Botany 48:469-474. 1958.

STOMAYOR, I.A., PURDY, L.M. \& TRESE, A.T. Infection of sugarcane leaves by Puccinia melanocephala. Phytopathology 73:695-699. 1983.

TAYLOR, P.W.J. Evidence for the existence of single race of common rust caused by Puccinia melanocephala in Australian sugar cane cultivars. Australian Journal of Agricultural Research 43:443-450. 1992. 